\title{
Role of neuro-sonography of peripheral nerves as a diagnostic and a differentiation tool of amyotrophic lateral sclerosis
}

\author{
Rana Zakaria Ahmed Mohamed ${ }^{1 *}$, Haitham Hamdy Salem', Hossam Moussa El-Sayed Sakr², \\ Hossam-Eldin Mahmoud Afifi ${ }^{1}$, Ahmed Mohammed Elsadek ${ }^{1}$ and Nagia Aly Fahmy ${ }^{1}$
}

\begin{abstract}
Background: Motor neuron disease is a heterogeneous group of progressive neurodegenerative disorders, most common of which is amyotrophic lateral sclerosis (ALS). There are many clinical and radiological criteria to diagnose amyotrophic lateral sclerosis and to differentiate it from other motor neuron disease and neurodegenerative disorders. Neuro-sonography is one of the easily applied tools to diagnose and differentiate ALS. ALS diagnosis is delayed up to 3 years according to some authors due to the wide differential diagnosis, with cervical degeneration being a common misdiagnosis. The objective of this study was to evaluate the role of neuro-sonography in diagnosis and differentiation of amyotrophic lateral sclerosis from other causes of progressive mixed upper and lower motor neuron lesion.
\end{abstract}

Results: A total neuro-sonography score at a cut-off point $(\leq 127)$ predicted patients with ALS, with good $(85 \%)$ accuracy, sensitivity $=73 \%$ and specificity $=83 \%(p<0.01)$ and Lt median arm score at a cut-off point $(\leq 6)$ predicted patients with ALS, with good (88\%) accuracy, sensitivity $=86 \%$ and specificity $=86 \%(p<0.01)$ and the median nerve at the arm level was the most sensitive and specific nerve to predict patients with ALS.

Conclusion: Neuro-sonography of peripheral nerves is a recent, noninvasive, accessible technique that can be used in early diagnosis of ALS.

Keywords: ALS, Neuro-sonography, Motor neuron disease, Neuro-imaging

\section{Background}

Neuro-sonography is an emerging neuro-imaging modality that allows evaluation of multiple peripheral nerves in a short time window as it often shows multifocal enlargement of nerves in demyelinating neuropathies [1]. Inflammatory demyelinating and axonal neuropathies may have distinctive sonographic patterns of nerve enlargement and appear to be influenced by treatment [2]. Ultrasonography of the peripheral nervous system is a relatively young area of interest in neurology, although it was already reported in the radiological literature in

\footnotetext{
*Correspondence: ranazakaria@med.asu.edu.eg; lifesun6@hotmail.com ${ }^{1}$ Neurology and Psychiatry Department, Neuromuscular Unit, Ain Shams University, Cairo, Egypt

Full list of author information is available at the end of the article
}

the 1980s [3]. It allows peripheral nerves to be visualized with excellent resolution and has proved to be reliable, effective, noninvasive and well tolerated. As many peripheral nerves run a superficial course, they are easily accessible to sonography, even very small nerves and fascicular patterns can be studied. Furthermore, nerves may be examined over a long course in a few minutes (e.g., the median nerve from wrist to axilla) [3]. Nerve sonography has been applied to amyotrophic lateral sclerosis (ALS) demonstrating evidence of both nerve root and distal peripheral nerve atrophy [4]; this offers potential for ultrasound-based differentiation of ALS and ALS-mimicking disorders characterized by enlarged nerves [5].
Springer Open

(c) The Author(s) 2021. Open Access This article is licensed under a Creative Commons Attribution 4.0 International License, which permits use, sharing, adaptation, distribution and reproduction in any medium or format, as long as you give appropriate credit to the original author(s) and the source, provide a link to the Creative Commons licence, and indicate if changes were made. The images or other third party material in this article are included in the article's Creative Commons licence, unless indicated otherwise in a credit line to the material. If material is not included in the article's Creative Commons licence and your intended use is not permitted by statutory regulation or exceeds the permitted use, you will need to obtain permission directly from the copyright holder. To view a copy of this licence, visit http://creativecommons.org/licenses/by/4.0/. 


\section{Methods}

An observational case-control study with 90 participants, 30 of them suffering from amyotrophic lateral sclerosis presenting at our hospitals, and 30 subjects with cervical degeneration diagnosed by MRI cervical spine who presented to general neurology and neuromuscular clinics of our hospitals in the period between April 2018 till April 2020 and 30 healthy controls with unremarkable neurological history and examination.

Inclusion criteria:

- Age: 16 years or older.

- Sex: males and females.

For the cases:

- The diagnosis of ALS according to El Escorial World Federation of Neurology Criteria for the Diagnosis of ALS [6].

- Subjects with symptoms and signs of cervical disc degeneration diagnosed by MRI cervical spine and should be for a period of 3 months at least.

For the controls:

- The control group consisted of 30 healthy volunteers with age and sex matched to cases.

Exclusion criteria:

- Subjects with metabolic diseases complicated with neurological symptoms such as diabetes mellitus, chronic kidney disease, inflammatory liver disease, subjects taking drugs known to affect peripheral nerves, etc.

- Subjects with congenital neurological involvement.

\section{Technique of nerve ultrasound}

Nerve ultrasound was performed using logiq p7 ultrasound machine (GE healthcare, Waukesha, Wisconsin, USA) with a linear transduced $(7-12 \mathrm{MHz})$.

Cross-sectional area of the following nerves was measured: the median nerve-at the carpal tunnel, at the mid-level of the forearm and the upper arm; the ulnar nerve-at the Guyon's canal, at the mid-level of the forearm and the upper arm; the radial nerve at the spiral grove; the posterior tibial nerve at the tarsal tunnel, and the tibial nerve at the popliteal fossa.
Table 1 Socio-demographic data among 90 subjects

\begin{tabular}{ll}
\hline Variables & Frequency (\%) \\
\hline Age (years) & $46.4 \pm 14.8^{*}$ \\
Gender & \\
Female & $33(36.7 \%)$ \\
Male & $57(63.3 \%)$ \\
\hline
\end{tabular}

${ }^{*}$ Mean \pm SD

\section{Statistical analysis}

Data entry, processing and statistical analysis was carried out using MedCalc ver.18.11.3 (MedCalc, Ostend, Belgium). Tests of significance (ANOVA, Chi-square tests, Pearson's correlation, and ROC-curve analysis) were used. Data were presented and suitable analysis was done according to the type of data (parametric and nonparametric) obtained for each variable. P-values less than $0.05(5 \%)$ was considered to be statistically significant. P $>0.05$ : non-significant (NS), $\mathrm{P}<0.05$ : significant $(\mathrm{S}), \mathrm{P}<$ 0.01: highly significant (HS).

\section{Results}

Ninety participants were included in this study where the mean age of all subjects was $(46.4 \pm 14.8)$ years. Regarding gender of the patients, the majority (63.3\%) of patients were males, while (36.7\%) were females. By using ROC-curve analysis, total neuro-sonography score at a cut-off point $(\leq 127)$ predicted patients with ALS, with good (85\%) accuracy, sensitivity of $73 \%$ and specificity of $83 \%(\mathrm{p}<0.01)$.

\section{Clinical data}

This table shows that; the mean age of all patients was $(46.4 \pm 14.8)$ years. Regarding gender of the patients, the majority $(63.3 \%)$ of patients were males, while $(36.7 \%)$ were females (Table 1).

Regarding presenting symptoms, $3.3 \%$ of patients had dysphagia, hand drop, nasal tonation and orthopnea, $10 \%$ had foot drop and paraparesis, $6.7 \%$ had quadriparesis, and $60 \%$ had weakness.

Regarding site of onset, $13.3 \%$ of patients had bulbar and lumbar onset, $6.7 \%$ had cervical onset, $36.7 \%$ had LL onset, and $30 \%$ had UL onset.

Regarding neurological symptoms, $30 \%$ of patients had bulbar affection, $73.3 \%$ had cervical affection, $16.7 \%$ had thoracic affection, $83.3 \%$ had lumbar affection, 20\% had cognitive affection using MoCA test, and $36.7 \%$ had extra motor affection such as numbness and muscle cramps (Table 2).

Regarding basic clinical data, $43.3 \%$ of patients were smokers, $26.7 \%$ had positive consanguinity and 33.3\% had positive family history (Table 3 ). 
Table 2 Neurological symptoms among 30 ALS patients

\begin{tabular}{llc}
\hline Variables & & Frequency (\%) \\
\hline Presenting symptoms & Dysphagia & $1(3.3 \%)$ \\
& Foot drop & $3(10 \%)$ \\
& Hand drop & $1(3.3 \%)$ \\
& Nasal tonation & $1(3.3 \%)$ \\
& Orthopnea & $1(3.3 \%)$ \\
& Paraparesis & $3(10 \%)$ \\
& Quadriparesis & $2(6.7 \%)$ \\
Weakness & $18(60 \%)$ \\
Site of onset & Bulbar & $4(13.3 \%)$ \\
& Cervical & $2(6.7 \%)$ \\
& LL & $11(36.7 \%)$ \\
Bulbar affection & Lumbar & $4(13.3 \%)$ \\
Cervical affection & UL & $9(30 \%)$ \\
Thoracic affection & + ve & $9(30 \%)$ \\
Lumbar affection & + ve & $22(73.3 \%)$ \\
Cognitive affection & + ve & $5(16.7 \%)$ \\
Extra-motor affection & + ve & $25(83.3 \%)$ \\
\hline
\end{tabular}

UL upper limb, LL lower limb

Table 3 Basic clinical results among 30 ALS subjects

\begin{tabular}{llc}
\hline Variables & & Frequency (\%) \\
\hline Smoking & + ve & $13(43.3 \%)$ \\
Consanguinity & + ve & $8(26.7 \%)$ \\
Family history & $+v e$ & $10(33.3 \%)$ \\
\hline
\end{tabular}

Regarding neurological data, the average age of onset was $42.4 \pm 15.4$ years, the average disease duration was $1.8 \pm 1.4$ years, the average ALS-FRS scale was $37.2 \pm$ 8.4 .

Regarding clinical phenotypes, $6.7 \%$ of patients had bulbar phenotype, $63.3 \%$ had classic phenotype, $23.3 \%$ had classic/familial phenotype, and 3.3\% had flail chest and local segment (Table 4).

Comparative study between the 3 groups revealed highly significant increase in age in cervical group, compared to other groups $(\mathrm{p}=0.011)$ (Fig. 1$)$.

Comparative study between the 3 groups revealed nonsignificant difference as regards sex of patients $(\mathrm{p}>0.05)$ (Table 5, Fig. 2).

\section{Neuro-sonography data}

Comparative study between the 3 groups revealed highly significant decrease in total UL, LL and overall
Table 4 Neurological clinical results among 30 ALS subjects

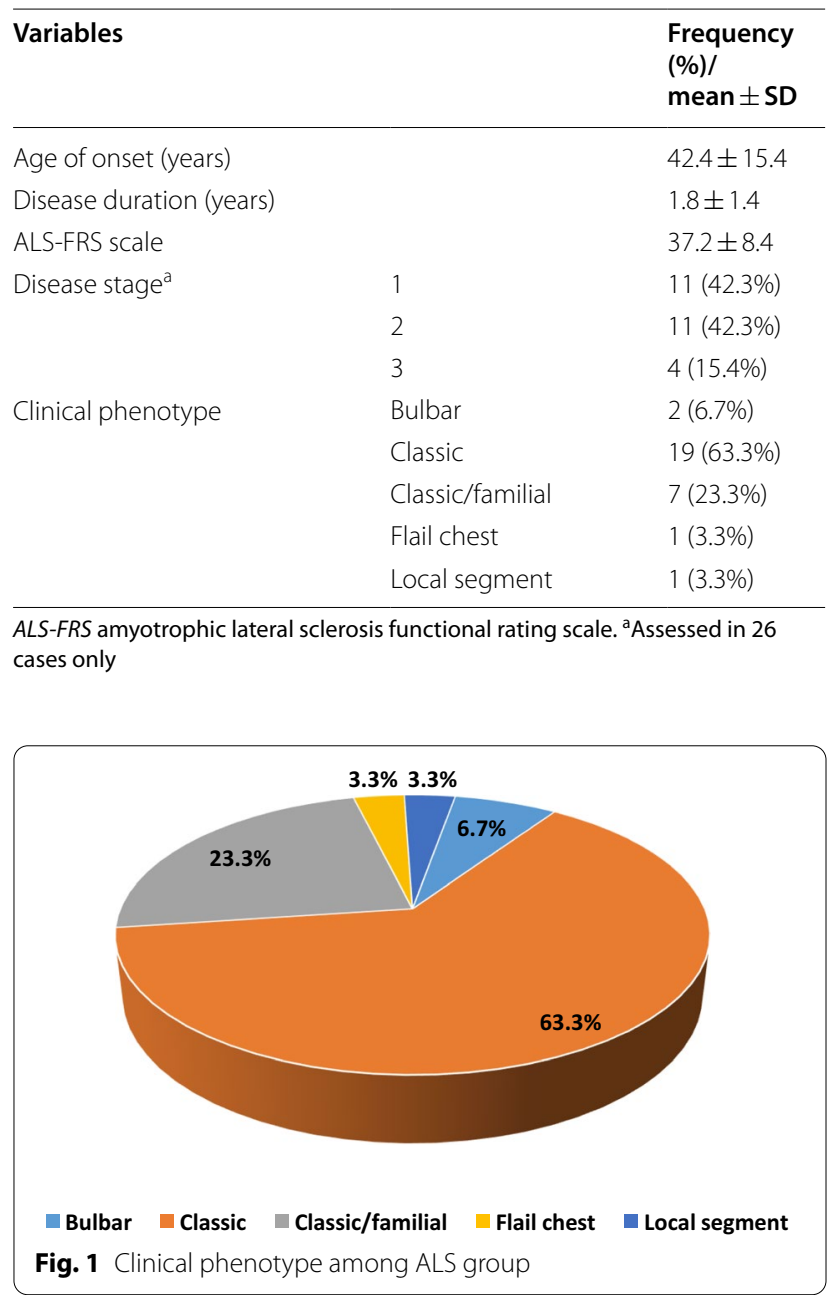

neuro-sonography score measurements in ALS group, compared to other groups ( $\mathrm{p}<0.01$, respectively) (Table 6; Figs. 3, 4, 5).

Pearson's correlation analysis shows that disease duration had a highly significant negative correlation with total neuro-sonography score in (cervical group) $(\mathrm{p}=0.0016)$ (Table 7; Fig. 6).

By using ROC-curve analysis, total neuro-sonography score at a cut-off point $(\leq 127)$ predicted patients with ALS, with good (85\%) accuracy, sensitivity of $73 \%$ and specificity of $83 \%(\mathrm{p}<0.01)$ (Table 8$)$.

Pearson's correlation analysis shows that all factors had a non-significant correlation (Table 9).

Pearson's correlation analysis shows that age had a non-significant correlation with total neuro-sonography score in (control group) ( $p>0.05$ ) (Table 10).

The median and ulnar nerves are the most affected nerves in ALS patients as shown in Table 11, Fig. 7. 
Table 5 Comparison between the three groups as regards socio-demographic results using ANOVA and Chi-square tests

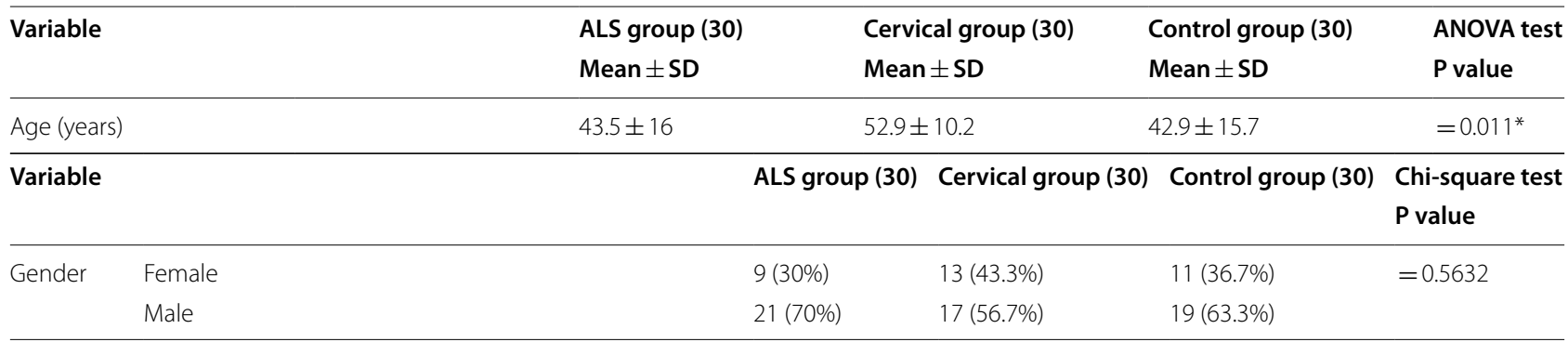

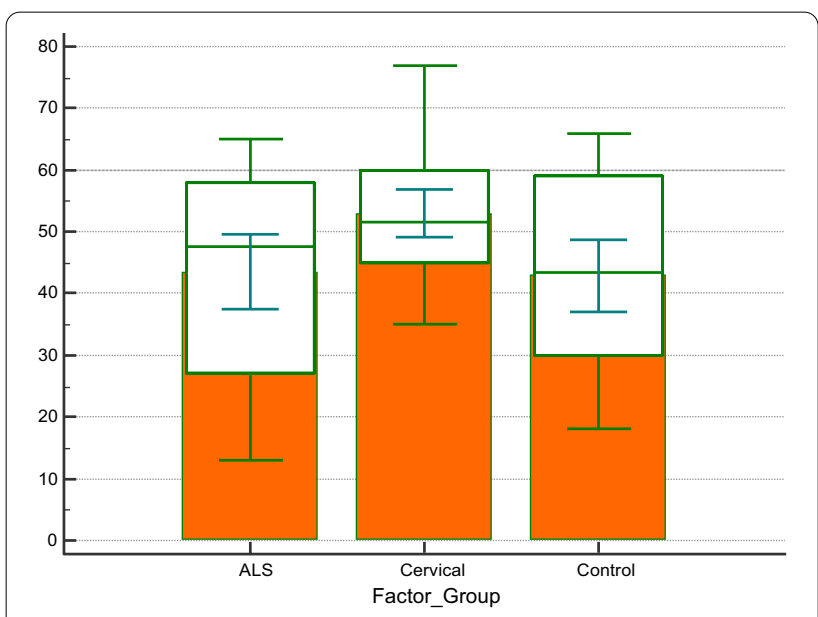

Fig. 2 Comparison between three groups regarding age
Table 6 Comparison between the three groups as regards (total) neuro-sonography data using ANOVA test

\begin{tabular}{lllll}
\hline Variable & $\begin{array}{l}\text { ALS group } \\
\text { (30) }\end{array}$ & $\begin{array}{l}\text { Cervical } \\
\text { group } \\
\text { (30) } \\
\text { Mean } \pm \text { SD }\end{array}$ & $\begin{array}{l}\text { Control } \\
\text { group } \\
\text { (30) }\end{array}$ & ANOVA test \\
Mean \pm SD & P value \\
\hline $\begin{array}{l}\text { Total UL } \\
\text { score }\end{array}$ & $74.5 \pm 14.3$ & $94.6 \pm 16$ & $96 \pm 9.5$ & $<0.001$ \\
$\begin{array}{l}\text { Total LL score } \\
\text { Total neuro- } \\
\text { sonography }\end{array}$ & $40.8 \pm 115.4 \pm 22.8$ & $53.8 \pm 11.7$ & $48.4 \pm 11.7$ & $<0.001$ \\
score & & $148.5 \pm 24.3$ & $145.4 \pm 15.5$ & $<0.001$ \\
\hline
\end{tabular}

\section{Discussion}

The primary objective of this study is to assess the neuro-sonography for diagnosis and differentiation of amyotrophic lateral sclerosis. This is a conventional

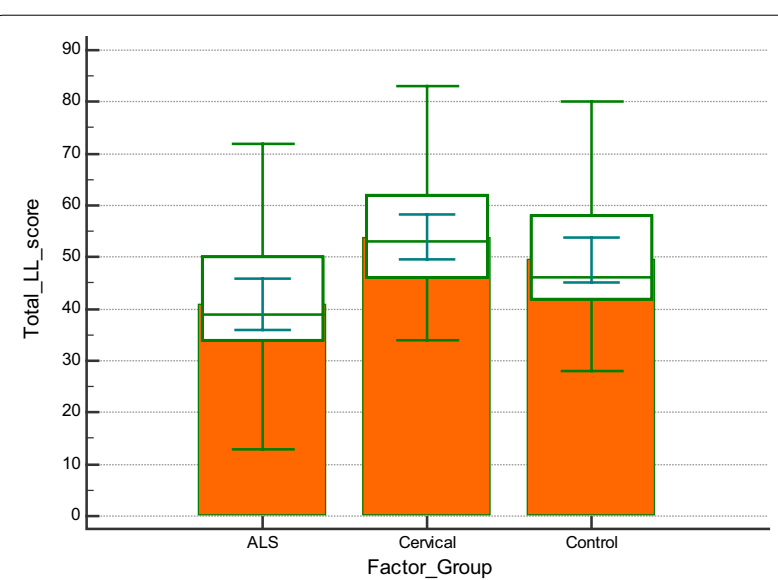

Fig. 4 Comparison between the three groups as regards total LL score
Fig. 3 Comparison between the three groups as regards total UL score 


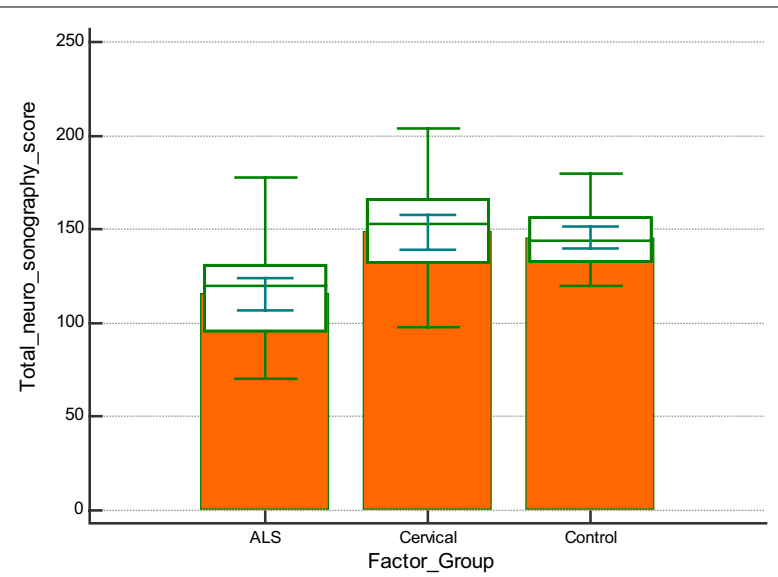

Fig. 5 Comparison between the three groups as regards total neuro-sonography score

case-control study conducted on 90 patients attending to Ain-Shams University Hospitals.

To our knowledge, this is the first comparative neurosonography study to assess differentiation of ALS and cervical degeneration subjects presented with similar clinical picture.

In our study, we also worked on the neuro-sonography cross-sectional area of both lower limbs' peripheral nerves in addition to both upper limbs, which is scarcely preceded by other studies.

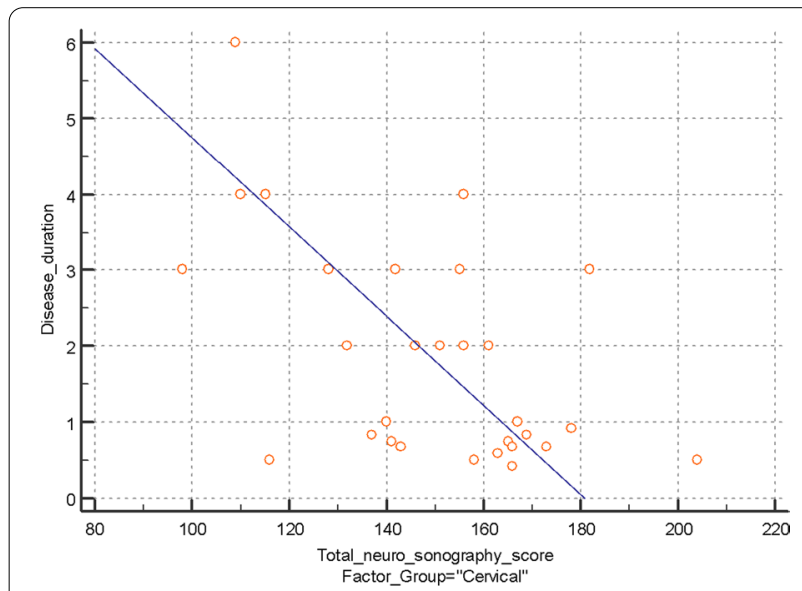

Fig. 6 Correlation between cervical group disease duration and total neuro-sonography score

Peripheral nerve atrophy as reported on group-level in most of the ultrasound studies comparing ALS and healthy controls most likely reflects axonal degeneration in ALS, but correlation studies between ultrasound and histopathology are thus far lacking.
Table 7 Pearson's correlation analysis for some basic factors associated with total neuro-sonography score in (cervical group)

\begin{tabular}{lll}
\hline Associated factor & \multicolumn{2}{l}{ Total neuro-sonography score } \\
\cline { 2 - 3 } & $\mathbf{R}$ & $\mathbf{P}$ \\
\hline Age (years) & -0.07527 & $=0.6926$ \\
Disease duration (years) & -0.5499 & $=0.0016$ \\
\hline
\end{tabular}

r: Pearson's rho (correlation coefficient)

Our findings goes in accordance with other authors who also found out that ALS could be prevalent in specific age group with specific subtypes and gender; ALS is characterized by a sexual dimorphism, the most obvious being the higher risk of developing the disease in men [7]. More subtle differences between the two sexes have been reported both in ALS preclinical models and in humans [8].

Age is the strongest risk factor of ALS as found out by [7], 8]. It has been found out that the median age at onset is 67.1 years, Bulbar phenotype was correlated with older age, where women were more affected than men at increasing ages, while classic phenotype, on the contrary, was associated with younger age, where the risk in men increased with age, PUMN was correlated with younger age, flail arm phenotype was associated with male sex and less strongly with younger age and finally, respiratory phenotype was correlated with male sex and showed a trend toward a higher frequency in older age [9].

The spread of lesions across the CNS in ALS has been explained either as a neuroanatomical contiguous propagation in the upper and lower motor neurons, with random onset in discrete body regions [10] or as a prion-like propagation, with either contiguous or noncontiguous diffusion [11] or, finally, as a sequential pattern of spread of TDP43 pathology with a corticofugal mechanism [12].

Further aspects that have contributed to the large variance of the available nerve ultrasound data include the lack of standardized imaging protocols and ratings.

In our study, we compared our results to normal values reported by [13] that the mean median nerve CSAs \pm SD at the distal wrist crease was $7.2 \pm 1 \mathrm{~mm}^{2}$; mid-forearm $4.8 \pm 0.9 \mathrm{~mm}^{2}$; mid-arm $6.1 \pm 1 \mathrm{~mm}^{2}$; axilla $5.9 \pm 0.9$ $\mathrm{mm}^{2}$, while average ulnar nerve CSAs distal wrist crease, $5.9 \mathrm{~mm}^{2}$; arterial split, $6.3 \mathrm{~mm}^{2} ; 2 \mathrm{~cm}$ distal to tip of the medial epicondyle, $6.4 \mathrm{~mm}^{2}$; tip of the medial epicondyle, $6.5 \mathrm{~mm}^{2} ; 2 \mathrm{~cm}$ proximal to tip of the medial epicondyle, $6.7 \mathrm{~mm}^{2}$; mid-humerus, $6.1 \mathrm{~mm}^{2}$; and axilla, $6.2 \mathrm{~mm}^{2}$, as reported by [14].

The mean cross-sectional areas of the radial nerves reported by [15] were as follows: at $4 \mathrm{~cm}$ at the lateral epicondyle of the humerus $(4 \mathrm{~cm}), 5.14 \pm 1.24 \mathrm{~mm}^{2}$; and 
Table 8 ROC-curve of (total) neuro-sonography data to predict patients with ALS

\begin{tabular}{lllllll}
\hline Variable & AUC & E & $\begin{array}{l}\text { Best cut-off point } \\
\text { (criterion) }\end{array}$ & Sensitivity (\%) & Specificity (\%) & P value \\
\hline Total UL score & 0.855 & 0.0426 & $\leq 90$ & 86.67 & 73.33 & $<0.0001$ \\
Total LL score & 0.747 & 0.0592 & $\leq 41$ & 63.33 & 81.67 & $<3.33$ \\
Total neuro-sonography & 0.859 & 0.0428 & $\leq 127$ & 73.33 & & $<0.0001$ \\
score & & & & &
\end{tabular}

$R O C$ receiver operating characteristic, $A U C$ area under curve, $S E$ standard error

Table 9 Pearson's correlation analysis for some basic factors associated with total neuro-sonography score in (ALS group)

\begin{tabular}{lll}
\hline Associated factor & \multicolumn{2}{l}{ Total neuro-sonography score } \\
\cline { 2 - 3 } & $\mathbf{R}$ & $\mathbf{P}$ \\
\hline Age (years) & -0.1769 & $=0.3496$ \\
Age of onset (years) & -0.1515 & $=0.4243$ \\
Disease duration (years) & -0.2125 & $=0.2684$ \\
ALS-FRS scale & 0.1663 & $=0.3977$ \\
\hline
\end{tabular}

r: Pearson's rho (correlation coefficient)

Table 10 Pearson's correlation analysis for some basic factors associated with total neuro-sonography score in (control group)

\begin{tabular}{lll}
\hline Associated factor & \multicolumn{2}{l}{ Total neuro-sonography score } \\
\cline { 2 - 3 } & $\mathbf{r}$ & $\mathbf{P}$ \\
\hline Age (years) & -0.2887 & $=0.1218$ \\
\hline
\end{tabular}

r: Pearson's rho (correlation coefficient)

at mid-humerus (midpoint between the elbow crease and axilla), $5.08 \pm 1.23 \mathrm{~mm}^{2}$

Regarding tibial nerve at the popliteal fossa 19 $\mathrm{mm}^{2} \pm 6.9$, tibial nerve at the level of the medial malleolus $12.7 \mathrm{~mm}^{2} \pm 4.5$, common peroneal nerve at the popliteal fossa $9.5 \mathrm{~mm}^{2} \pm 4$, common peroneal nerve fibular head $8.9 \mathrm{~mm}^{2} \pm 3.2$, sural nerve $3.5 \mathrm{~mm}^{2} \pm 1.4$ [16].

Schreiber et al., compared nerve CSA between ALS and controls, similarly reporting peripheral nerve atrophy in ALS affecting the ulnar nerve at the wrist, the median nerve at the forearm, and the ulnar, median and radial nerves in the upper arm [17].

However, not all studies are in agreement on which nerves are reduced at which sites. One group reported pronounced atrophy of the distal ulnar nerve [18]; Noto et al. did not find a reduction of ulnar nerve size in ALS [19]

Mori et al., also found that the cervical root and peripheral nerve CSA atrophy seem thereby to occur in all ALS disease phenotypes independent of the degree of UMN
Table 11 Neuro-sonography results among 30 ALS subjects

\begin{tabular}{llll}
\hline Variables & & Mean & SD \\
\hline Rt UL & Rt median wrist & 6.66 & 2.33 \\
& Rt median forearm & 6.56 & 2.19 \\
& Rt median arm & 6.81 & 1.93 \\
& Rt ulnar wrist & 5.82 & 1.84 \\
& Rt ulnar forearm & 6.05 & 1.94 \\
& Rt ulnar epicondyle & 6.87 & 2.49 \\
\multirow{2}{*}{ Rt LL } & Rt radial & 5.01 & 2 \\
& Rt tibial ankle & 9.77 & 3.46 \\
Lt UL & Rt tibial popliteal fossa & 13.95 & 5.22 \\
& Lt median wrist & 6.87 & 2.77 \\
& Lt median forearm & 6.46 & 1.7 \\
& Lt median arm & 6.8 & 1.97 \\
& Lt ulnar wrist & 6.01 & 1.75 \\
& Lt ulnar forearm & 6.23 & 1.86 \\
& Lt ulnar epicondyle & 7.13 & 2.42 \\
& Lt radial & 5.08 & 2.12 \\
& Lt tibial ankle & 10.08 & 3.22 \\
Lt LL & Lt tibial popliteal fossa & 14.23 & 4.98 \\
& & &
\end{tabular}

This table shows that the mean value of each neuro-sonography variable measured by $\mathrm{mm}^{2}$

or LMN involvement or from the site of disease onset [20].

It was proposed that CSA enlargement of the four nerves yielded an optimal combined sensitivity and specificity to discriminate between ALS and MMN. Goedee et al. later stated that

CSA enlargement of even just two nerves should be accurate enough to distinguish between the two diseases [21].

The total neuro-sonography score at a cut-off point $(\leq 127)$ predicted patients with ALS with good $(85 \%)$ accuracy, sensitivity of $73 \%$ and specificity of $83 \%$ (p < 0.01 ). This shows the significance of neuro-sonography as a diagnostic and differentiation tool in neurodegenerative diseases and neuromuscular diseases as well, and this goes in agreement with other authors such as [22], who found out that the cross-sectional area of the median nerve in the mid-arm was smaller in the ALS group than 

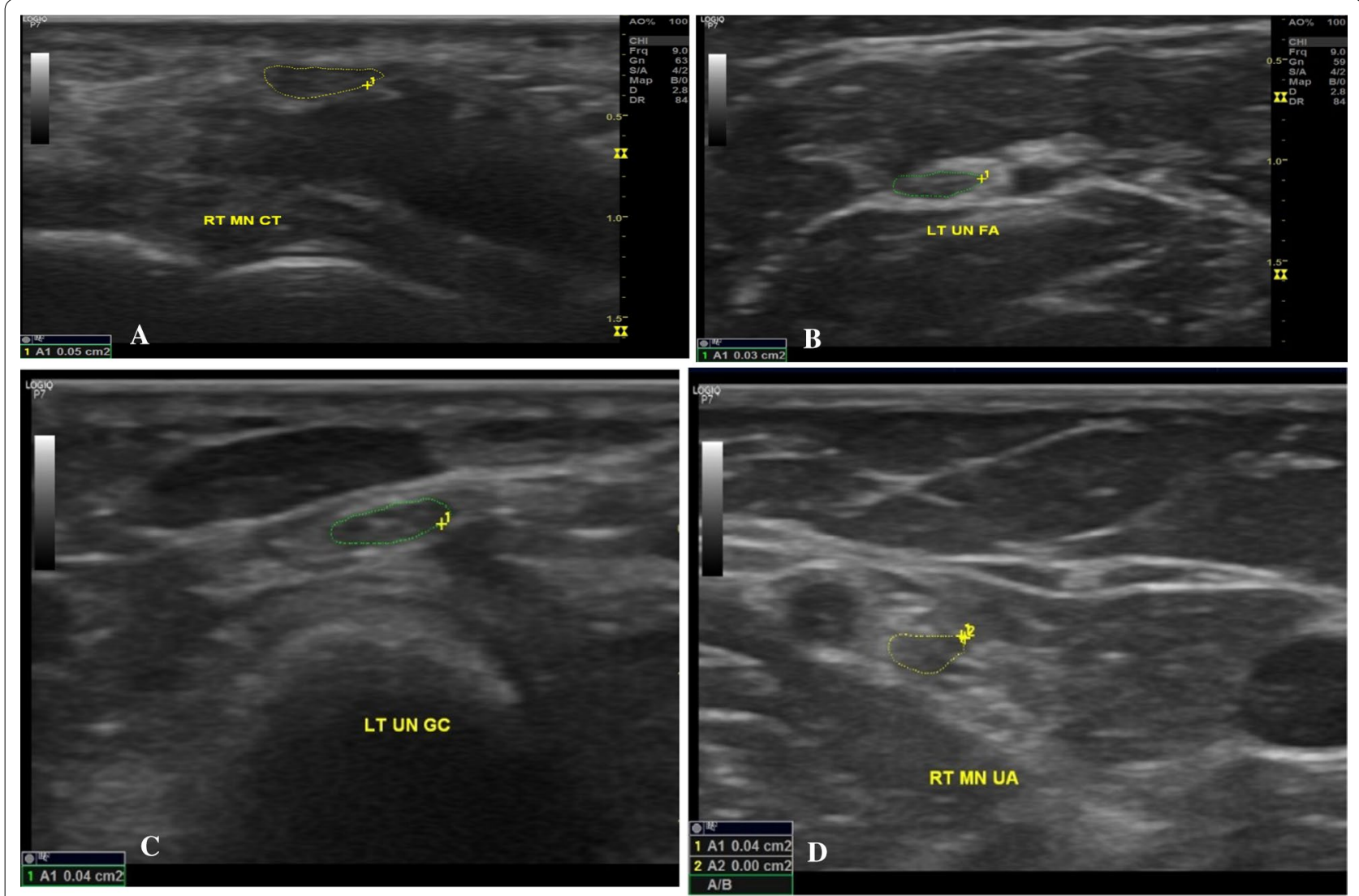

Fig. 7 Showing ultrasound image of median and ulnar nerves in different levels denoting atrophy in ALS patients. A Right median nerve in carpal tunnel. B Left ulnar nerve in forearm. C Left ulnar nerve in Guyon's canal. D Right median nerve in upper arm

controls $\left(10.5 \mathrm{~mm}^{2}\right.$ vs $\left.12.7 \mathrm{~mm}^{2}, \mathrm{p}=0.0023\right)$. This also goes in accordance with [18] who found out that compared with controls, ALS patients had significant, distally pronounced reductions of ulnar CSA (forearm/ wrist level) across all disease groups, except for PLS and median nerve CSA (forearm/wrist level) did not differ between controls and ALS while ulnar nerve ultrasound in ALS subgroups revealed significant differences in distal CSA values, which suggests it has value as a marker of LMN involvement. Its potential was particularly evident in the UMND and PLS groups, which can be hard to separate clinically.

\section{Conclusions}

Neuro-sonography is an evolving and promising tool in diagnosis and differentiation of amyotrophic lateral sclerosis and other neurodegenerative such as cervical degeneration and it is recommended as an ancillary tool to aid in history and clinical examination.

\section{Abbreviations}

ALS: Amyotrophic lateral sclerosis; MRI: Magnetic resonance imaging; Lt.: Left; Rt.: Right; UL: Upper limb; LL: Lower limb; FRS: Functional rating scale; DM: Diabetes mellitus; HTN: Hypertension; SD: Standard deviation; CSA: Crosssectional surface area; CNS: Central nervous system; PUMN: Predominant upper motor neuron; UMN: Upper motor neuron; LMN: Lower motor neuron; MMN: Multi focal motor neuropathy; PLS: Primary lateral sclerosis; UMND: Upper motor neuron disease; MoCA: Montreal cognitive assessment test.

\section{Acknowledgements}

Not applicable.

\section{Authors' contributions}

R.Z., H.M. Elsayed, H.H.S, H.M.A, A.M.E., N.A.F., conceived the study and participated in its design and coordination and helped to draft the manuscript. H.M.A. participated in the design of the study and performed the statistical analysis. All authors have read and approved the manuscript.

\section{Funding}

Not applicable.

\section{Availability of data and materials}

Dataset is available as master sheet in Excel format and publicly available in Neurology department, Ain Shams University through communicating corresponding author. 


\section{Declarations}

Ethical approval and consent to participate

The study protocol was approved by Ain Shams University, Faculty of Medicine Research Ethic Committee FWA 000017585 in 2018. Written informed consent was obtained from the patients participating in the study.

\section{Consent for publication}

Not applicable.

\section{Competing interests}

All authors declare that they do not have any competing interests.

\section{Author details}

${ }^{1}$ Neurology and Psychiatry Department, Neuromuscular Unit, Ain Shams University, Cairo, Egypt. ${ }^{2}$ Radiology Department, Ain Shams University, Cairo, Egypt.

Received: 11 June 2021 Accepted: 24 September 2021

Published online: 06 November 2021

\section{References}

1. Grimm A, Heiling B, Schumacher U, Witte OW, Axer H. Ultrasound differentiation of axonal and demyelinating neuropathies. Muscle Nerve. 2014;50:976-83.

2. Goedee HS, Brekelmans GJ, Visser LH. Multifocal enlargement and increased vascularization of peripheral nerves detected by sonography in CIDP: a pilot study. Clin Neurophysiol. 2014;125:154-9.

3. Beekman R, Visser LH, Verhagen WI. Ultrasonography in ulnar neuropathy at the elbow: a critical review. Muscle Nerve. 2011;43:627-35.

4. Schreiber S, Dannhardt-Stieger V, Henkel D. Quantifying disease progression in amyotrophic lateral sclerosis using peripheral nerve sonography. Muscle Nerve. 2016. https://doi.org/10.1002/mus.25066.

5. Loewenbrück KF, Liesenberg J, Dittrich M, Schäfer J, Patzner B, Trausch B, Machetanz J, Hermann A, Storch A. Nerve ultrasound in the differentiation of multifocal motor neuropathy (MMN) and amyotrophic lateral sclerosis with predominant lower motor neuron disease (ALS/LMND). J Neurol. 2016;263(1):35-44.

6. Brooks BR. El escorial World Federation of Neurology criteria for the diagnosis of amyotrophic lateral sclerosis. J Neurol Sci. 1994;124:96-107.

7. Chio A, Mora G, Moglia C, et al. Secular trends of amyotrophic lateral sclerosis: the Piemonte and Valle d'Aosta register. JAMA Neurol. 2017;74:1097-104.

8. Chiò A, Manera U, D'Ovidio F, Grassano M, Corrado MBL, D'Alfonso S, et al. ALS phenotype is influenced by age, sex, and genetics, a populationbased study. Neurology. 2020;94(8):e802e810. https://doi.org/10.1212/ WNL.000000000008869.

9. Al-Chalabi A, Hardiman O, Kiernan MC, Chiò A, Rix-Brooks B, van den Berg LH. Amyotrophic lateral sclerosis: moving towards a new classification system. Lancet Neurol. 2016:15:1182-94.

10. Ravits JM, La Spada AR. ALS motor phenotype heterogeneity, focality, and spread: deconstructing motor neuron degeneration. Neurology. 2009;73:805-11.
11. Sekiguchi T, Kanouchi T, Shibuya K, et al. Spreading of amyotrophic lateral sclerosis lesions: multifocal hits and local propagation? J Neurol Neurosurg Psychiatry. 2014;85:85-91.

12. Brettschneider J, Arai K, Del Tredici K, et al. TDP-43 pathology and neuronal loss in amyotrophic lateral sclerosis spinal cord. Acta Neuropathol. 2014; 128:423-37

13. Bathala L, Kumar P, Kumar K, Shaik A, Visser LH. Normal values of median nerve cross-sectional area obtained by ultrasound along its course in the arm with electrophysiological correlations, in 100 Asian subjects. Muscle Nerve. 2014;49(2):284-6. https://doi.org/10.1002/mus.23912 (PMID: 23703739).

14. Cartwright MS, Shin HW, Passmore LV, Walker FO. Ultrasonographic findings of the normal ulnar nerve in adults. Arch Phys Med Rehabil. 2007;88(3):394-6. https://doi.org/10.1016/j.apmr.2006.12.020 (PMID: 17321837)

15. Chen J, Wu S, Ren J. Ultrasonographic reference values for assessing normal radial nerve ultrasonography in the normal population. Neural Regen Res. 2014;9(20):1844-9. https://doi.org/10.4103/1673-5374.143433.

16. Bedewi MA, Abodonya A, Kotb M, Kamal S, Mahmoud G, Aldossari K, Alqabbani A, Swify S. Estimation of ultrasound reference values for the lower limb peripheral nerves in adults: a cross-sectional study. Medicine. 2018:97(12): e0179. https://doi.org/10.1097/MD.0000000000010179.

17. Schreiber S, Schreiber F, Garz C, Debska-Vielhaber G, Assmann A, Perosa V, et al. Toward in vivo determination of peripheral nervous system immune activity in amyotrophic lateral sclerosis. Muscle Nerve. 2019;59:567-76.

18. Schreiber S, Abdulla S, Debska-Vielhaber G, Machts J, DannhardtStieger V, Feistner H, Oldag A, Goertler M, Petri S, Kollewe K, Kropf S, Schreiber F, Heinze HJ, Dengler R, Nestor PJ, Vielhaber S. Peripheral nerve ultrasound in amyotrophic lateral sclerosis phenotypes. Muscle Nerve. 2015;51(5):669-75. https://doi.org/10.1002/mus.24431 (Epub Mar 14 PMID: 25155020)

19. Noto Yl, Garg N, Li T, Timmins HC, Park SB, Shibuya K, Shahrizaila N, Huynh W, Matamala JM, Dharmadasa T, Yiannikas C, Vucic S, Kiernan MC. Comparison of cross-sectional areas and distal-proximal nerve ratios in amyotrophic lateral sclerosis. Muscle Nerve. 2018;58(6):777-783. https:// doi.org/10.1002/mus.26301.

20. Mori A, Nodera H, Takamatsu N, Maruyama-Saladini K, Osaki Y, Shimatani $Y$, et al. Sonographic evaluation of cervical nerve roots in ALS and its clinical subtypes. J Med Invest. 2016;63:54-7.

21. Goedee HS, van der Pol WL, van Asseldonk J-TH, Franssen $H$, Notermans NC, Vrancken AJFE, et al. Diagnostic value of sonography in treatmentnaive chronic inflammatory neuropathies. Neurology. 2017:88:143-51.

22. Cartwright MS, Walker FO, Griffin LP, Caress JB. Peripheral nerve and muscle ultrasound in amyotrophic lateral sclerosis. Muscle Nerve. 2011;44(3):346-51. https://doi.org/10.1002/mus.22035.

\section{Publisher's Note}

Springer Nature remains neutral with regard to jurisdictional claims in published maps and institutional affiliations.

\section{Submit your manuscript to a SpringerOpen ${ }^{\circ}$ journal and benefit from:}

- Convenient online submission

- Rigorous peer review

- Open access: articles freely available online

- High visibility within the field

- Retaining the copyright to your article

Submit your next manuscript at springeropen.com 